\title{
Federalização da Universidade do Paraná: a voz dissonante de Plínio Tourinho
}

\author{
The federalization of the University of Paraná: Plínio Tourinhos's \\ dissonant voice
}

\author{
Névio de Campos ${ }^{1}$ \\ Eliezer Felix de Souza ${ }^{2}$
}

RESUMO

Este artigo trata do problema da federalização do ensino superior no Paraná, privilegiando um olhar sobre a posição de Plínio Tourinho que fez defesa do ensino superior livre em 1950, durante o processo de federalização da Universidade do Paraná. Assim, reconstitui a narrativa dessa personagem que posicionou-se contrariamente à federalização do ensino superior, apoiando-se na entrevista concedida por ele ao inquérito sobre a federalização e na produção acadêmica que aborda os debates e as políticas do ensino superior no Brasil. Esta análise evidencia que Plínio Tourinho contrapôs-se à federalização da Universidade do Paraná, sem deixar de defender a manutenção e ampliação da subvenção estatal, caracterizando uma visão de ensino particular com forte reverberação na história da educação brasileira.

Palavras-chave: Ensino Superior. Universidade do Paraná. Liberdade de Ensino. Plínio Tourinho.

\section{ABSTRACT}

This article deals with making higher education oficial in Paraná. It highlights Plínio Tourinho's attitude when defending free higher education in 1950, during the process of federalizing the University of Paraná. This article reconstitutes his story: he was against nationalizing higher education as can be seen in the interview he gave at the investigation on federalization. This can also be seen in his academic works which approach the debates as well as the policies on higher education in Brazil. This analysis shows that Plínio Tourinho was contrary to federalizing the University of Paraná, whilst maintaining his defense of the continuation and the expansion of state subsidies, establishing a view of private education which strongly resonated in the history of Brazilian education.

Keywords: Higher Education. University of Paraná. Educational Freedom. Plínio Tourinho.

\footnotetext{
1 Universidade Estadual de Ponta Grossa, Pós-Doutor em História (UFPR). Doutor em Educação (UFPR). Professor do Programa de Pós-Graduação em Educação da Universidade Estadual de Ponta Grossa, Paraná. Pesquisador Produtividade CNPq. E-mail: ndoutorado@yahoo.com.br

2 Universidade Estadual de Ponta Grossa. Doutor em Educação (UEPG). E-mail: eliezer.felix@hotmail.com
} 


\section{Introdução}

Este texto objetiva trazer à discussão o caso da federalização da Universidade do Paraná (UP), ocorrida em 1950, enfatizando um olhar sobre a posição do professor Plínio Tourinho. Este debate está associado à história do ensino superior paranaense, em específico a atual Universidade Federal do Paraná. Desde 1950 ela integra o sistema federal de ensino superior, pois nos últimos anos da década de 1940 houve uma movimentação articulada entre lideranças políticas e intelectuais do Brasil com a finalidade de transformar instituições particulares, estaduais e municipais em universidades federais. A primeira a ser transformada foi a Universidade de Minas Gerais, em dezembro de 1949. Em dezembro de 1950 a UFPR foi federalizada, juntamente com a Federal do Rio Grande do Sul e a Federal da Bahia.

A historiografia da educação apresenta uma síntese bastante significativa a respeito do ensino superior no Brasil, ao destacar que as primeiras experiências de faculdades datam do período posterior à vinda da Família Real Portuguesa, houve predominância de faculdades e escolas isoladas, assim como existiu intensa discussão e disputa para proibir ou permitir a criação de universidades. Esses elementos ajudam a entender porque as tentativas de criação de universidades demoraram a lograr êxito, pois mesmo ao serem fundadas, voltaram a funcionar na condição de faculdades isoladas, como foi o caso da Universidade do Paraná, criada em 1912 e obrigada pela Lei Maximiliano ao desmembramento em Faculdade de Medicina, Faculdade de Direito e Faculdade de Engenharia, a partir de 1915. Somente em 1946 voltou a ser Universidade, após aglutinação das três indicadas anteriormente com a Faculdade de Filosofia, Ciências e Letras.

No final dos anos 1940 teve início o processo de federalização de universidades particulares, cujo movimento se fez presente no ensino superior paranaense (CAMPOS, 2008). Esse movimento resultou em considerável mudança no ensino superior, pois houve aumento das taxas de matrícula de 12,4\% ao ano entre 1945 e 1964 (CUNHA, 1989, p. 93). De acordo com esse autor (1989, p. 93), "foi a ampliação das matrículas nas escolas públicas existentes, e a criação de novas, que respondeu pela maior parte dessa expansão". Para ele, "em 1954, já em crescimento acelerado, as escolas e universidades públicas abrangiam $59,7 \%$ das matrículas, chegando a 61,3\%, em 1964" (CUNHA, 1989, p. 93). Naquele contexto, merece destaque, conforme Ana Waleska Mendonça (2002, p. 142) que:

\footnotetext{
O número de universidades existentes no país cresceu de 5, em 1945, para 37, em 1964. Essas universidades continuavam a nascer do processo de agregação de escolas profissionalizantes, como é o caso das nove universidades católicas que se constituíram. Na sua maioria, entretanto, eram universidades federais, criadas através do processo de federalização de faculdades estaduais ou particulares. A maioria das atuais universidades federais existentes hoje tem nesse processo a sua origem.
} 
No que diz respeito à história do ensino superior do Paraná da primeira metade do século XX, destacamos os livros Universidade do Mate: história da UFPR, de Ruy Christovam Wachowicz e Intelectuais paranaenses e as concepções de universidade (18921950), de Névio de Campos, Reflexões UFPR 100 anos (1912-2012), organizada por Renato Lopes Leite e Ricardo de Oliveira. Neste debate inscreve-se este artigo, buscando retratar a posição contrária do professor Plínio Tourinho à federalização da UP. Trata-se de um aspecto específico, sem deixar de estabelecer diálogo com a produção existente, em particular com a pesquisa intitulada Flávio Suplicy de Lacerda: relações de poder no campo acadêmico/político paranaense e o processo de federalização e modernização da Universidade do Paraná (1930-1971), escrita por Eliezer Felix de Souza e com o manuscrito Um inquérito sobre a federalização da Universidade do Paraná (1950), de Névio de Campos e Eliezer Felix de Souza.

Em uma parte de sua investigação, Felix de Souza discute o processo de federalização da UP, especificamente ao tratar da atuação do então reitor Flávio Suplicy de Lacerda. No manuscrito, Souza e Campos apresentam um recorte que debate o inquérito sobre a federalização da universidade paranaense, organizado pelo jornal Gazeta do Povo. Os dois historiadores identificam a composição quase unânime de autoridades políticas e da comunidade acadêmica em prol da federalização. Pela exposição dos autores, é possível perceber que de todos os participantes do inquérito, apenas Plínio Tourinho não manifestou concordância com o processo de federalização. Assim sendo, neste momento, intenta-se avançar nessa discussão, na tentativa de explicitar a posição contrária à federalização manifestada pelo professor Plínio Tourinho e as razões para a sua discordância.

A construção argumentativa apoia-se na entrevista concedida por Plínio Tourinho ao inquérito da federalização da universidade paranaense, publicado no jornal Gazeta do Povo e nas atas da Faculdade de Engenharia do Paraná. Os dados são interpretados no âmbito da discussão a respeito do direito de criação de universidade, entre o final do século XIX e a primeira metade do século XX, como atestam as pesquisas acadêmicas de (BARROS, 1986; CAMPOS, 2008; CUNHA, 1986; FÁVERO, 2000, 2006). Essa confrontação ganhou dimensões ampliadas, em particular no campo da política educacional com as reformas Rivadávia Correa (1911) e Maximiliano (1915) que materializaram as duas posições em curso no Brasil: de um lado, uma visão flexível de política educacional, permitindo o direito a todo brasileiro de criar universidades; de outro, uma concepção menos permissiva que criava alguns condicionantes à livre iniciativa no campo do ensino superior. Nos anos 1930, o debate na esfera do ensino superior ganhou forte reverberação, em especial com o fechamento da Universidade do Distrito Federal (UDF) e a criação da Universidade do Brasil 
como modelo nacional, bem como a criação da Universidade de São Paulo (MENDONÇA, 2002; PAULA, 2002; EVANGELISTA, 2002).

Essa abordagem inscreve-se nos estudos que tomam o jornal diário como fonte para a pesquisa em História da Educação, privilegiando a relação entre intelectuais e imprensa. Esse aspecto está associado à ideia de que "para a intelectualidade a imprensa representa um ofício, um meio de expressão e uma forma de promoção social. Ela permitiu ao intelectual, em diferentes contextos, marcar presença na cena pública para além dos espaços restritos dos círculos de letrados" (VIEIRA, 2007, p. 15). No contexto brasileiro e paranaense essa presença ganhou notabilidade, a partir da década de 1920, conforme atestam (CAPELATO, 1994; CAPELATO; PRADO, 1980; LUCA, 2005; MARTINS; LUCA, 2008; VIEIRA, 2007, 2013; BONTEMPI JÚNIOR, 2005, 2017). A educação foi uma das agendas da imprensa e dos intelectuais. Nesse aspecto, a pauta do ensino superior, também, se fez presente. Assim sendo, "[...] o desejo dessa imprensa moderna de permanecer atuante na esfera política levou-a a engajar-se em projetos sociais, com base na produção de slogans de campanhas nas quais o grau de assentimento público fosse significativo" (VIEIRA, 2007, p. 21). É nessa articulação entre os textos da imprensa paranaense e os contextos que se pretende reconstituir o debate a respeito da federalização da UP, em particular a posição dissonante de Plínio Tourinho.

\section{De Professor a Diretor da Faculdade de Engenharia (1912- 1950)}

Plínio Alves Monteiro Tourinho (1882-1950) é paranaense, nascido em Curitiba no dia 08 de fevereiro e falecido em 29 de agosto, nessa mesma cidade. Sua vida é marcada por atuação em inúmeras atividades, como pertencimento ao exército brasileiro e atuação no campo da política (deputado federal da Constituinte de 1934). Entretanto, ele é mais conhecido pela longa trajetória docente na UP, consubstanciada entre 1912 e 1950, aspecto a ser destacado nesta narrativa.

É importante assinalar que ele descendia de uma família com relativa importância no quadro cultural e político paranaense, pois seu pai (chegou ao posto de capitão) e avô paterno (chegou ao posto de coronel) tinham formação superior em engenharia e pertenciam ao quadro do exército. Ele ficou órfão de pai aos três anos de idade. Seu pai, Francisco Antonio Monteiro Tourinho, faleceu em 1885, com 48 anos. A família paterna é originária do Rio de Janeiro. O pai de Plínio Tourinho se estabeleceu no Paraná devido ao exercício das atividades de engenheiro, antes com passagem por São Paulo e Santa Catarina. Ele integrou as equipes responsáveis por diversas obras e ações públicas, entre 
elas a Estrada da Graciosa que ligaria Curitiba ao litoral paranaense. Chegou ao Paraná em 1867, casando-se com Maria Leocádia Alves, originária do litoral do Paraná. Aos quinze anos Plinio Tourinho ficou órfão de mãe, supondo-se ter sido amparado pelo seu irmão Mario Tourinho e/ou por sua irmã Themira Tourinho, respectivamente onze anos e nove anos mais velhos do que ele.

Ele ingressou no exército sob o beneplácito de seu irmão que já pertencia ao quadro militar, desde 1886. Antes de ingressar no exército, estudou no Ginásio Paranaense. Após, entrou na Escola Militar de Rio Pardo (RS), onde cursou o ensino secundário. Depois disso, foi para Escola Militar do Rio de Janeiro, na qual em 1906, saiu Alferes-aluno na arma de artilharia. Em 1910, matriculou-se no curso de Engenharia Militar e Estado Maior, concluindo o curso superior, em 1912. Observa-se que segue a posição de seu pai e irmão mais velho, ao cursar ensino superior e ocupar altas patentes no exército. Esse aspecto evidencia o investimento em capital cultural à medida que o acesso ao diploma universitário caracterizava um valor positivo à sua família. É importante dizer que "o Exército brasileiro no século XIX, [constituiu-se em] uma força em vias de profissionalização - como muitos dos demais Exércitos nacionais do Ocidente" (SHULZ, 1994, p. 9 apud ALVES, 2011, p. 87).

Esses aspectos familiares indicam alguma aproximação à tipologia das famílias tradicionais do Paraná e do Brasil, pois conforme Ricardo Oliveira (2002, p. 49), "a existência de patentes nas ordenanças era a regra social. Era uma classe militarizada e quase todos eram conhecidos pelo posto nas ordenanças". Igualmente aos seus ascendentes, ele integrou a carreira militar, chegando à patente de coronel e passando à reserva em 1940. Na condição de militar participou do movimento da Revolução de 1930 que culminou no Governo Vargas e na nomeação de seu irmão mais velho (Mario Alves Monteiro Tourinho) para interventor no Paraná. Em 1933, ele próprio fez parte dos quadros políticos ao ser eleito deputado da constituinte nacional que discutiu e aprovou a Constituição de 1934. Nesse ano, foi eleito deputado federal, cargo exercido até a implantação do Estado Novo.

Além dessas atividades, fez parte das corporações da engenharia civil, em particular do Instituto de Engenharia do Paraná. No âmbito do ensino superior teve sua vida associada à história da UP, participando da sua criação e exercendo papel de liderança acadêmica e política na Faculdade de Engenharia (uma das integrantes da universidade paranaense). Ele integrou o grupo fundador da UP e acumulou atividades do magistério com as demais funções. Na Faculdade de Engenharia foi catedrático da Cadeira de Astronomia e Geodésia, fixando-se na disciplina de Trigonometria Esférica, Geodésia e Astronomia. Além disso, compôs o Conselho Superior da UP, desde sua fundação, conforme atesta Relatório Geral 
do ano de 1913. Ele foi escolhido para paraninfo da primeira turma formada no Curso de Engenharia, cujo discurso foi publicado na Revista Acadêmica (1919).

$\mathrm{Na}$ Faculdade de Engenharia foi eleito diretor, em 1930, mas declinou da indicação. Essa recusa pode estar associada a sua participação no âmbito da representação política no Paraná e na esfera federal. A não aceitação abriu espaço para outro docente assumir a Faculdade de Engenharia. Conforme Eliezer F. de Souza (2016, p. 48), "durante toda a década de 1930, Arnaldo Beckert teve domínio como Diretor da Faculdade". Por outro lado, na década seguinte, Tourinho passou a ter grande força política, quando exerceu dois mandatos consecutivos na direção dessa Faculdade (1946-1950). Nos anos de 1940, a referida faculdade teve a seguinte direção:

Quadro 1 - Composição da diretoria no período de 1940 a 1950

\begin{tabular}{|c|c|}
\hline Durval de Araújo Ribeiro & 1940 a 1946 - três gestões sucessivas \\
\hline Plínio Alves Monteiro Tourinho & 1946 a 1950 - duas gestões sucessivas \\
\hline João Moreira Garcez & Setembro a outubro de 1950 \\
\hline
\end{tabular}

Fonte: Puppi (1986, p. 79).

Durval Ribeiro não concluiu seu terceiro mandato. Em ata da Congregação de 6 de julho de 1946 registrou-se Plínio Alves Tourinho como Diretor substituto. $\mathrm{Na}$ ata consta requerimento do Diretor da Faculdade, Durval Ribeiro, dirigido à Congregação, solicitando três meses de licenciamento por motivos de ordem particular. Manifestou-se Plínio Tourinho para lamentar:

Que a Faculdade tenha que se privar durante um trimestre da assistência orientadora, decidida, devotada e idealista de Durval Ribeiro, estabelecendo esse afastamento uma solução de continuidade em uma gestão fecunda de grandes e felizes empreendimentos (FE, ata 6 jul. 1946).

Diante disso, coube a Plínio Tourinho o término da gestão de Durval Ribeiro. $\mathrm{Na}$ ata da Congregação, realizada em 3 de dezembro de 1946, é possível observar os motivos do afastamento do professor Durval Ribeiro: "lamentamos pelo falecimento da esposa do professor Durval Ribeiro" (FE, ata 3 dez. 1946). Plínio Tourinho continuou na direção da Faculdade até 15 de dezembro de 1946, quando foi realizada nova eleição. Feita a votação, contabilizaram-se 16 votos para Plínio Tourinho e 1 voto para Durval Ribeiro, sendo o primeiro eleito para o período compreendido entre 19 de dezembro de 1946 a 18 de dezembro de 1948. Consumado o ato eleitoral, o professor Flávio Suplicy de Lacerda declarou que "seu voto não visou apenas render uma homenagem ao abnegado fundador e 
continuador da Faculdade. Buscou também realçar as virtudes do professor Plínio, exemplo e estímulo para nós todos". Suplicy ainda destacou:

\begin{abstract}
A diretoria da Faculdade deparava com um espírito superior ao Paraná, espírito que jamais se arredou da luta e que não obstante seu grande acervo de dignificantes serviços prestados à sociedade e a nação, subtrai-se as seduções de um tentador conformismo, na hora atual de marcante comodismo (FE, ata 15 dez. 1946).
\end{abstract}

João Moreira Garcez, nos mesmos tons, saudou o professor Plínio Tourinho: "este é um grande dia para a Faculdade, motivo de grande alegria a eleição unânime verificada" (FE, ata 15 dez. 1946). Diante dos elogios, Tourinho "agradeceu a distinção de que foi alvo, frisou o peso da investidura que lhe é confiada na hora atual, em que se avolumam as responsabilidades do diretor de Faculdade em face do crescente e já elevado número de matrículas nas diversas séries da Faculdade" (FE, ata 15 dez. 1946). Dois anos mais tarde, antes do novo pleito, observam-se palavras elogiosas a Plínio Tourinho, sendo que os professores Moreira Garcez, Algacyr Maeder e Flávio Suplicy propõem que ele seja reeleito por aclamação. Na defesa desse ato, Flávio Suplicy argumentou: "excepcionalmente, pode a congregação, por deliberação unânime, contrariar, em caso como a fluente, disposição do Regimento interno" (FE, ata $15 \mathrm{dez}$. 1948). Dessa forma, Suplicy de Lacerda afirmou: "para realçar o mérito do professor Plínio Tourinho e para melhor expressar-lhe adoração e as homenagens da Congregação, seja extra regimentalmente Tourinho aclamado Diretor da Faculdade para o biênio a iniciar-se no próximo 19 de dezembro" (FE, ata 15 dez. 1948). Após essa fala foi aclamada salva de palmas de todos os presentes. O diretor Plínio Tourinho agradeceu o prestígio perante a Faculdade de Engenharia do Paraná, cujo novo mandato se estenderia até 1950.

É importante assinalar que, em ata de 18 de junho de 1948, há registro de indicação do nome de Plínio Tourinho para composição da nova reitoria da UP. Segundo o registro, "coube ao professor Moreira Garcez a indicação de Plínio Tourinho, além da convincente justificação do proponente, sólidas argumentações dos professores Durval Ribeiro do Amaral e Flávio Suplicy de Lacerda" (FE, ata 18 jun. 1948). Ele foi aclamado pela Congregação da Faculdade de Engenharia a integrar a nova reitoria, na condição de vicereitor. No entanto, Plínio Tourinho decidiu-se não aceitar essa indicação. No pleito de 1948 para reitoria previa-se que a Faculdade de Direito indicaria o nome ao cargo de reitor e a Faculdade de Engenharia um docente a função de vice-reitor.

Desses aspectos da trajetória de Plínio Tourinho, o primeiro destaque é sua relação com os fundadores da UP. Conforme evidenciam Campos (2008) e Wachowicz (1983), a UP foi criada pela composição das Faculdades de Engenharia, Direito e Medicina e estava amparada juridicamente na Lei Rivadavia Corrêa que estabeleceu a liberdade para criação 
de universidades no país. De modo contundente os professores da UP defendiam essa Lei por ter estabelecido a livre iniciativa no âmbito do ensino superior. Essa ideia pode ser observada em trecho do discurso de paraninfo promovido por Plínio Tourinho à formatura da primeira turma de Engenharia, publicado na Revista Acadêmica:

\begin{abstract}
Foi assim, que sob os auspícios da liberrima e benefica lei orgânica do ensino, iniciaram-se os nossos primeiros passos, sem que a parte de seu distincto magisterio houvesse a sediça preoccupação de distribuir diplomas decorativos e sim diffundir um estudo solido, proficuo, que satisfizesse as multiplas e variadas necessidades da vida pratica, sempre complexa e ardua para o engenheiro, ante 0 quadro de dificuldade a suprir (TOURINHO, 1919, p. 13).
\end{abstract}

Entretanto, poucos anos depois da sua criação, a história da UP foi abreviada pela Lei Maximiliano (1915). Diante disso, os professores combateram com muita intensidade essa reforma, conforme explicita Plínio Tourinho:

Em nosso paiz, ao envez de se dar plena liberdade em materia de ensino superior, que apenas deve ser fiscalizado pelo poder central para garantia da moralidade, impera ainda o estulto principio de que as pequenas capitaes de nossos Estados, não comportam taes centros de ensinamentos e dahi se percebe o descaso, a verdadeira indifferença com que em seu início foi recebida a idéa de fundação de um estabelecimento dessa ordem, por aquelles apegados a esse errôneo preconceito (TOURINHO, 1919, p. 12).

Plínio Tourinho, na parte inicial de seu discurso de paraninfo, explicitou a crítica a Lei Maximiliano:

\begin{abstract}
Hoje que a grandeza de nosso estabelecimento está definitivamente firmada, é bom deixar assignalado que, a instabilidade e descontinuidade administrativas de nosso governos, muito tem concorrido para prejudicar a livre expansão de importantes iniciativas particulares, pois em materia de ensino superior, depois de attingirmos ao mais alto grau de desenvolvimento com a Lei Rivadavia, volvemos ao passado, para de novo ficar esse ensino acorrentado ao centro de uma commissão de eruditos, que de muito longe, neste país tão grande, pretende com criterio estapafurdio, impor a sua soberana vontade, menoscabando do saber alheio, querendo de um só relance, sem inquirir, tudo abranger, sem siquer aquilatar da idoneidade moral e material dos estabelecimentos que têm vida propria, corpo docente digno e que portanto merecem alguma attenção de sua parte (TOURINHO, 1919, p. 14).
\end{abstract}

Após a Reforma Maximiliano, ao lado de outras principais lideranças da UP, Tourinho trabalhou em defesa do reconhecimento das Faculdades de Medicina, de Direito e de Engenharia, assim como nas frentes que postulavam a restauração da Universidade, conforme atesta Névio de Campos (2008, 2013a).

Além disso, a sua notabilidade é observada quando assumiu a direção da Faculdade de Engenharia (1946). No intervalo de sua gestão (1946-1950) poderia ter sido alçado ao cargo de vice-reitor, não fosse sua decisão de rejeitar a indicação feita pelos seus colegas da Faculdade de Engenharia. A que se deveu a sua não aceitação? Nos registros da ata de 18 de junho de 1948 dessa Faculdade não há indícios das razões da recusa à indicação da composição de candidatura à vice-reitoria. A sua recusa implicou na indicação de Flávio 
Suplicy de Lacerda, também professor da Faculdade de Engenharia. Suplicy foi eleito pela Congregação da Universidade a vice-reitor, passando a reitor um ano mais tarde, em razão do falecimento do titular João Ribeiro de Macedo Filho. Depois disso, Suplicy de Lacerda manteve-se à frente da Universidade do Paraná até 1971, exceto no intervalo que foi ministro da Educação do governo Castello Branco.

Uma das possibilidades da não aceitação de indicação de seu nome ao cargo de vicereitor poderia estar relacionada à sua idade avançada e às condições de saúde, pois como atesta ata da Congregação de 13 de fevereiro de 1948, em solenidade de recepção de visita do Presidente da República Eurico Gaspar Dutra, não pode se fazer presente por restrição médica, sendo representado na ocasião pelo professor Algacyr Munhoz Maeder. Ele não ascendeu ao cargo de vice-reitor, mas manteve-se à frente da Faculdade de Engenharia e sustentou sua posição contrária à federalização da UP, conforme se verá no item seguinte.

\section{Posição de Plínio Tourinho sobre a Federalização da UP}

A voz dissonante de Plínio Tourinho está circunscrita ao processo de federalização da UP, em específico ao debate estabelecido pelo inquérito publicado na Gazeta do Povo. O referido inquérito deve ser compreendido no âmbito do movimento de federalização que embalava as discussões no interior das congregações das faculdades e nos conselhos da UP. Tão logo ela foi restaurada, ocorrida em 1946, passou a existir defesa de sua federalização. A partir de 1948, sob a direção do professor João Ribeiro de Macedo Filho, essa ideia passou a ganhar consideração. Mas foi sob a direção de Flávio Suplicy de Lacerda que esse movimento ganhou intensidade, pois ele catalisou diferentes autoridades em prol da federalização.

Os jornais da capital paranaense participaram de modo intenso desse processo, denominado pela Gazeta do Povo de a "batalha da federalização". A imprensa começou a ter um papel de destaque na vida social, principalmente no período que marcou a passagem do século XIX para o século XX, pois foi um momento caracterizado pelas transições de pequenas a grandes empresas jornalísticas nos principais centros urbanos brasileiros. Sua atuação passou a traduzir as novas ideias e os hábitos gerados pelas transformações vivenciadas pela população, tornando-se espaço privilegiado para a discussão dos problemas e rumos da sociedade. Nesse sentido, "o jornal impresso diário é parte de uma estrutura midiática de enorme impacto e cada vez mais, diversificada ação política e cultural" (VIEIRA, 2007, p. 14). Nesses termos, de acordo com Carlos Eduardo Vieira (2007, p. 13), "a imprensa permite uma ampla visada da experiência citadina: dos personagens ilustres 
aos anônimos, do plano público ao privado, do político ao econômico, do cotidiano ao evento, da segurança pública às esferas cultural e educacional”.

Os jornais seriam os "provocadores" da opinião pública. Marco Morel (2008, p. 33) interroga-se acerca do significado de opinião pública. Ele destaca que "há quem a tome de forma literal como personagem ou agente histórico dotado de vontade, tendência e iniciativa próprias". Para ele, "a expressão opinião pública é polissêmica - também polêmica" (MOREL, 2008, p. 33). A chamada opinião pública não é recente no jornalismo e suas principais características datam das duas primeiras décadas do século XVIII na Europa. Carlos Eduardo Vieira argumenta que o conceito de opinião pública está associado à questão da modernidade. Para ele, "a modernidade foi concebida pelos seus principais arautos como a ação edificante da razão que - por meio da ciência, da tecnologia, da instrução e das políticas sociais - universalizaria um novo modo de pensar e agir" (VIEIRA, 2007 , p. 19). Nesse aspecto, os jornais representariam um importante aliado, não só no papel de incentivador de manifestações pedagógicas, como ainda exerceriam a importante função de polemização.

A campanha pela federalização, lançada por Flávio Suplicy, recebeu na imprensa paranaense a imagem de "um momentoso assunto" e de "batalha da federalização". Logo após o lançamento oficial do movimento de federalização, em reunião do Conselho Universitário, ocorrida em 19 de dezembro de 1949, a Gazeta do Povo publicou que o Reitor Flávio Suplicy de Lacerda:

[...] o ilustre paranaense conclamou a todos para a batalha da federalização, sonho dos batalhadores desse empreendimento que tanto orgulha o Paraná. Assim é que, desde já, estamos todos nós, empenhados nessa luta que nos trará vantagens (GAZETA DO POVO, 21 dez. 1949, grifo nosso).

Alguns dias mais tarde, a repercussão dessa campanha pôde ser percebida em nova matéria:

Está já no conhecimento público o conteúdo da concisa e, não obstante, vibrante conclamação do Magnífico Reitor da Universidade do Paraná, o distinto professor Flávio Lacerda a professores, universitários, ex-alunos, entidades culturais e ao povo para se unirem àquela grande instituição para o esforço comum de conseguir a reparação de grave injustiça contra nós, ao excluí-la o Congresso dos benefícios da federalização (GAZETA DO POVO, 30 dez. 1949).

Para o jornal, o anúncio da federalização das Universidades com a "inclusão de todas as escolas do país" no projeto de federalização "posta a margem apenas a Universidade do Paraná [...] chocou vivamente a consciência universitária de nossa terra" (GAZETA DO POVO, 30 dez. 1949). A consequência dessa exclusão: 
Provocou imediata, enérgica, embora serena reação tão oportuna, tão bela, tão eficientemente manifestada por sua Magnificência, o Sr. Reitor, num dos momentos mais solenes e empolgantes da vida daquele esplêndido Instituto de ensino superior (GAZETA DO POVO, 30 dez. 1949).

No entendimento do periódico, a manifestação de Suplicy de Lacerda "atingiu todos os lares da nossa terra, dando o tremendo entrosamento de nossa sociedade com o mundo estudantil. Assim, desde o Governador do Estado, incluindo as classes culturais até o mais simples homem da rua" (GAZETA DO POVO, 30 dez. 1949). Neste sentido, a Gazeta do Povo, para sustentar a imagem de que estava ao lado dos universitários, dispôs a página do jornal "[...] aos nossos universitários para por ela veicularem seus anseios, reivindicações e realizações" (GAZETA DO POVO, $30 \mathrm{dez}$. 1949).

Essa posição articuladora pode ser observada, também, no jornal Diário da Tarde. Em matéria intitulada Uma campanha necessária e oportuna o periódico referenciou que o reitor da Universidade "[...] em plena e empolgante assembleia universitária, comemorativa de nossa emancipação política, lançou uma causa simpática e emocionante: a da Federalização da nossa gloriosa Universidade" (DIARIO DA TARDE, 28 dez. 1949). Segundo o jornal:

\begin{abstract}
Irrompeu esse movimento, justamente numa hora solidíssima, com uma urgente conclamação de nosso povo para a campanha energética em prol desse instituto, honra e orgulho de nossa terra? Porque por iniciativa do Governo Federal foi votado um projeto federalizando as Universidades e Escolas superiores do Brasil, excetuando a do Paraná. Por mais incrível que possa aparecer cruel de madrasta, ela aconteceu. [...] trata-se de uma sagrada e de sumo interesse do Paraná para toda a coletividade da terra dos pinheirais. Por isso, de esperar que a proclamação do Magnífico Reitor espalhe por todo o Paraná e instigue nossa gente a agir em defesa da nossa Universidade padrão de orgulho de nossa terra e que não deve ficar à margem das suas coirmãs do Brasil (DIARIO DA TARDE, 28 dez. 1949).
\end{abstract}

Em matéria intitulada Campanha da federalização da Universidade (GAZETA DO POVO, 27 dez. 1949), assinada pelo jornalista paranaense e professor da Faculdade de Direito, Raul Rodrigues Gomes, criticou-se "a exclusão de nossa Universidade do projeto de federalização de todas as instituições de ensino superior do Brasil". Segundo ele, "estendeuse essa medida de Estados poderosos como os de São Paulo, Minas, Rio Grande, Pernambuco e Bahia, e as modestas unidades com as do Amazonas, Piauí, Goiás, Ceara, Alagoas sob o pretexto da uniformização de suas diretrizes" (GAZETA DO POVO, 27 dez. 1949). Concluiu enfatizando:

\footnotetext{
A vibrante, entusiástica e vigorosa convocação do Magnífico Reitor deve ter ecoado, seguramente repercutiu no cérebro e no coração de todos os Paranaenses de modo que comece e se desenvolva até a vitória total e absoluta essa grande e gloriosa campanha pela nossa Universidade - momento cristalizador da nossa energia e da nossa devoção ao ideal, a cultura e ao progresso de nossa pátria (GAZETA DO POVO, 27 dez. 1949).
} 
Nas páginas anteriores observamos a repercussão na imprensa do lançamento do movimento de federalização da UP. Logo depois, nos primeiros dias do ano de 1950, em específico na edição de 6 de janeiro de 1950, a Gazeta do Povo noticiou que publicaria Um inquérito sobre a federalização da universidade, sob a coordenação de Raul Gomes, cuja preocupação central seria debater a oportunidade, a viabilidade e a indisponibilidade da federalização dessa instituição. Esse jornal anunciou que Raul Gomes sistematizou um conjunto de questões que seria endereçado a professores, discentes, representantes de instituições culturais e comerciais, na tentativa de obter uma síntese do que pensavam os paranaenses sobre esse movimento em prol da federalização.

$\mathrm{Na}$ edição de 18 de janeiro de 1950, observamos que as seguintes perguntas compunham o inquérito: "1) Como recebeu a notícia de que todas as Universidades do Brasil e suas escolas superiores foram federalizadas exceto a nossa? Que acha da campanha pela federalização? Que deve fazer para que esse plano seja realizado?" (GAZETA DO POVO, 18 jan. 1950). Tão logo anunciou a existência do inquérito, o periódico passou a divulgar os dados produzidos. Na edição de 15 de janeiro de 1950, em matéria intitulada $A$ federalização da Universidade: um inquérito entre os diretores, professores e alunos - Não se trata de um movimento escolar: É uma causa do Paraná... declarava-se: "GAZETA DO POVO começa hoje a divulgar o resultado de vasto inquérito entre diretores, professores e alunos dos diferentes cursos da Universidade do Paraná sobre a palpitante questão de sua imediata federalização" (GAZETA DO POVO, 15 jan. 1950). A organização desse inquérito produziu um efeito de sentido quase uníssono, em particular ao sintetizar: "os depoimentos que hoje começamos a publicar trazem a marca comovedora da unanimidade de opinião sobre aquela apaixonante causa por cuja integral vitória todos os paranaenses devem lutar denodadamente" (GAZETA DO POVO, 15 jan. 1950).

Em geral, os conteúdos dos pareceres são favoráveis ao processo de federalização (SOUZA; CAMPOS, 2017). Entretanto, é possível identificar na posição do professor Plínio Tourinho uma voz dissonante, embora não tenha criado obstáculo à federalização da instituição. A organização da publicação da entrevista desse professor está no mesmo número e na mesma página da entrevista concedida pelo professor Oswaldo Piloto. Pela exposição, o leitor acessa a voz dissonante, mas em seguida, a posição favorável do professor Piloto. Além disso, chama atenção a escrita do título que está em letras maiúsculas: "MAIS DUAS PROEMINENTES FIGURAS RESPONDEM À NOSSA 'ENQUETE': CORONEL PLÍNIO TOURINHO E PROFESSOR OSWALDO PILOTO” (GAZETA DO POVO, 19 jan. 1950). No título, Tourinho é apresentado apenas como Coronel. Pode ser um detalhe fortuito. Entretanto, parece ser importante observar isso, pois 
o jornal não faz um confronto agressivo à posição de Tourinho. Por outro lado, organiza a publicação do inquérito de modo que o leitor acesse as posições favoráveis à federalização como contraposição a Tourinho. Se Tourinho não foi apresentado como professor, Oswaldo Piloto foi assim denominado. Mais do que isso, logo após a entrevista de Tourinho, o jornal intitulou a enquete de Piloto, em letras maiúsculas, com os seguintes termos: "UMA ALMA DE EDUCADOR FALA SOBRE A FEDERALIZAÇÃO” (GAZETA DO POVO, 19 jan. 1950).

A entrevista de Tourinho é antecedida por alguns comentários introdutórios. O primeiro parágrafo destaca que "a campanha da federalização, orientada com mão de mestre pela personalidade irradiante de S. Magnificência o Snr. Reitor Dr. Flávio Lacerda, se desdobra numa cadência firme para a sua objetivação” (GAZETA DO POVO, 19 jan. 1950). Na sequência, observa que "as faculdades estão sendo convocadas e deverão se pronunciar quanto antes sobre esse momentoso problema paranaense" (GAZETA DO POVO, 19 jan. 1950). Mais forte é sua exposição ao informar que "a Faculdade de Direito do Paraná, dirigida pelo espírito democrático do professor Enéas Marques dedicou uma sessão de sua congregação a esse grande assunto. E seu voto foi unânime pela federalização da Universidade do Paraná" (GAZETA DO POVO, 19 jan. 1950).

As três sentenças acima indicam ao leitor que o processo de federalização senão a única possibilidade histórica, ao menos seria a melhor opção a escolher, na interpretação do referido jornal. Ademais, parece insinuar que as demais faculdades (Medicina, Engenharia, Filosofia, Ciências e Letras) demoraram a manifestar-se a respeito da federalização, destacando que a de Direito já havia feito. Raul Gomes (organizador do inquérito) pertencia à Faculdade de Direito. O efeito de sentido das últimas duas orações é forte, pois associam a posição da Faculdade de Direito ao espírito democrático, forçando assim que as demais se pronunciassem. Pelo exposto, é possível depreender a pretensão de ressaltar que as decisões das faculdades deveriam ser encaminhadas pela vontade do corpo docente e não do seu diretor.

É importante observar que, em 17 de janeiro de 1950, a Faculdade de Engenharia já havia deliberado pela federalização da UP. Não obstante, parece que o organizador do Inquérito ainda não sabia dessa decisão da congregação da referida Faculdade. Em ata do dia 17 de janeiro, o secretário relatou a reunião presidida por Plínio Tourinho, Diretor dessa instituição:

\footnotetext{
Expõe o senhor presidente o assunto determinante da convocação da presente sessão: tomar a Congregação conhecimento, discutir e pronunciar-se sobre as bases do plano de federalização da Universidade do Paraná, elaborada pela Reitoria e que será encaminhada ao Congresso Nacional, para ser transformada em projeto de lei (FE, ata 17 jan. 1950).
} 
A ata informa que o referido plano foi debatido item por item. Em geral, considera que a Congregação posicionou-se favorável, pois reconheceu como aceitáveis, sem deixar de mencionar as ressalvas e os adendos propostos. Portanto, no momento de publicação da posição de Plínio Tourinho, a Faculdade de Engenharia já havia deliberado em prol da federalização. $\mathrm{Na}$ mencionada ata não consta nenhuma consideração contrária à federalização, indicando a distinção entre aquilo que Tourinho compreendia ser mais adequado ao ensino superior e a forma de conduzir a discussão junto a Congregação da Faculdade dirigida por ele.

Após as sentenças de forte efeito, o jornal fez considerações elogiosas a respeito desse professor ao dizer que:

\section{O Paraná inteiro admira e respeita a figura imaculada do coronel Plínio Tourinho. Poude passar pela vida com sua incorruptibilidade, porém, sem aquela agressividade de Robespierre. Seu senso de humanidade, quer dizer de compreensividade, fazem dele uma criatura quase de exceção. Diretor da Faculdade de Engenharia, é um ídolo da mocidade (GAZETA DO POVO, 19 jan. 1950).}

O jornal trata de orientar o leitor a respeito da posição de Tourinho, ao afirmar que "sua palavra se reveste de grande importância, tanto mais que examina a federalização sob vários de seus aspectos. Aceita-a, mas faz ponderações e advertências" (GAZETA DO POVO, 19 jan. 1950). Pois, bem, vejamos quais foram as ponderações e advertências desse professor e os termos de sua aceitação. A resposta de Tourinho inicia assim: "atendendo à solicitação constante da carta de V. S., abaixo respondendo os quesitos formulados, externando sobre os mesmos o meu pensamento de professor da Faculdade de Engenharia" (GAZETA DO POVO, 19 jan. 1950). Em sentido contrário ao exposto no título do jornal, Plínio Tourinho explicita que sua posição origina-se da condição de professor. Nesse jogo de sentidos, é possível depreender uma disputa de posição. O professor Tourinho foi bastante didático na organização de seu parecer, identificando respostas as três indagações feitas.

De imediato, sustenta que:

I - Em princípio, nunca tive simpatias pela federalização do ensino superior, convencido de que as iniciativas e organizações particulares, quando bem amparadas pelo Poder Público e honestamente administradas, são menos onerosas e muito mais produtivas que as Instituições Oficiais (GAZETA DO POVO, 19 jan. 1950).

Nota-se que sua posição faz defesa da livre iniciativa no ensino superior. Se explicita sua posição política, isto é, a sua concepção do que seria a melhor organização do ensino, não deixa de demonstrar sua leitura concreta do processo de federalização, pois, diz: 
Independente desse meu modo de pensar, é entretanto de estranhar a exclusão da nossa Universidade do plano de federalização do ensino superior de muitas escolas e, por mais que medite, semelhante propósito não encontra fundamento ou qualquer justificativa razoável (GAZETA DO POVO, 19 jan. 1950).

Ao invés de manifestar estranhamento com a não federalização procurou dar maior relevo ao baixo valor de subvenção que o governo federal destinava à instituição paranaense:

\begin{abstract}
Todas as escolas do norte do País passaram para o regime federal, acarretando esse ato público, um dispêndio avaliado em mais de cinquenta milhões de cruzeiros enquanto que a subvenção federal de nossas escolas foi apenas acrescida de quinhentos mil cruzeiros (GAZETA DO POVO, 19 jan. 1950).
\end{abstract}

Ele asseverava que esse valor era uma "importância insignificante para fazer face às suas atuais necessidades" (GAZETA DO POVO, 19 jan. 1950). Observava, também, que o baixo valor da subvenção federal não se justificava, uma vez que:

Convém assinalar ainda que o Estado do Paraná, com uma população menor à de alguns grandes Estados, economicamente ocupa o 5으 ou 6일 lugar no seio da Federação, pois o Governo Central arrecada de sua população importância muito superior às despesas com os serviços que aqui mantêm (GAZETA DO POVO, 19 jan. 1950).

Ele advertia contra o afã da federalização ao destacar que "[...] a Universidade do Paraná é possuidora de um patrimônio elevado, construído de majestoso edifício, dotado de amplas salas, com acomodações para ministrar o ensino a um elevado número de alunos" (GAZETA DO POVO, 19 jan. 1950).

A posição de Tourinho seguia no que organizou como segunda parte: "II - O assunto é bastante complexo e tanto mais quando é certo que algumas escolas federais não estão contentes com essa situação, pela falta absoluta de autonomia financeira" (GAZETA DO POVO, 19 jan. 1950). Na sequência, tomava posição contrária à federalização, ao explicitar que:

\begin{abstract}
Entre a passagem integral para o Governo Federal e um aumento da subvenção capaz de melhorar as condições do nosso ensino, pronuncio-me a favor da segunda proposição, na convicção de que se com sacrifício fizemos tanto, com um pouco mais de auxílio Federal, que nos permitisse melhorar a situação atual dos professores, o progresso de nossa instituição não teria limites (GAZETA DO POVO, 19 jan. 1950).
\end{abstract}

Em nome da autonomia financeira defende a não federalização da UP. Além disso, mobilizou a ideia de risco de interferência política na UP, ao sustentar que "os estabelecimentos federalizados sofrem influência da política" (GAZETA DO POVO, 19 jan. 1950). Ademais, assinalou que "as iniciativas da administração esbarram com as normas pesadas da burocracia pública, que entravam o desenvolvimento das mais justas 
reivindicações" (GAZETA DO POVO, 19 jan. 1950). Ele utilizou-se do argumento de autoridade para reiterar sua posição:

Não é uma opinião isolada, a minha. O 1 Congresso de Engenharia reunido em 1945, aprovou a seguinte tese: "Recomenda ao Governo, como medida inicial e indispensável para a melhoria do ensino universitário do País, a concessão de plena autonomia didática, financeira e administrativa às Universidades, não excluindo os institutos componentes das mesmas Universidades, em tudo que diz respeito aos seus peculiares interesses" (GAZETA DO POVO, 19 jan. 1950).

Ele seguiu nessa linha argumentativa, ao apelar ao pronunciamento do professor Ary Torres que no Congresso de Engenharia fez o seguinte depoimento:

\begin{abstract}
Dê-se a autonomia às escolas que merecem, forneçam-se-lhes recursos e confie-se nos administradores. Frequentei algumas escolas estrangeiras e visitei muitas Universidades. Em nenhuma notei preocupações de leis ou regulamentos e tive a impressão de que todas gozavam de ampla liberdade para se organizarem e se desenvolverem de conformidade com suas tendências e necessidades do meio. Não sei porque no BRASIL devemos desprezar o exemplo das nações adiantadas (GAZETA DO POVO, 19 jan. 1950).
\end{abstract}

Após as objeções expostas, Tourinho reconheceu um efeito positivo do processo de federalização, ao destacar que "até o presente a federalização de Escolas Superiores tem consistido em melhorar os vencimentos dos professores, o que é muito justo, pela proeminente função que exercem no evolver das coletividades" (GAZETA DO POVO, 19 jan. 1950). No entanto, minimizou essa conquista ao dizer que "o ensino em si, continua a ser deficiente pela falta de recursos indispensáveis ao aparelhamento" (GAZETA DO POVO, 19 jan. 1950).

No terceiro item de sua resposta, novamente defendeu a continuidade da UP nas mãos de grupos particulares:

\begin{abstract}
III - Se fosse possível obtermos um auxílio Federal capaz de melhorar as nossas condições atuais, sem prejuízo da autonomia financeira que tem sido o fator primordial do progresso do Ensino Superior no PARANÁ, resolveríamos com vantagens o problema que tanto nos preocupa (GAZETA DO POVO, 19 jan. 1950).
\end{abstract}

Além disso, asseverou que "sendo pensamento do Governo o centralizar todos os grandes empreendimentos, amarrando-os à burocracia administrativa que tanto prejudica o evolver do País, outro não há, senão o de aceitar a federalização" (GAZETA DO POVO, 19 jan. 1950). Na parte final de sua entrevista indicou a percepção de que a federalização da UP seria efetivada, reconhecendo que "a reitoria da Universidade está[va] agindo com muito critério, procurando ressalvar os direitos dos atuais professores bem como o próprio patrimônio que tanto nos custou a adquirir" (GAZETA DO POVO, 19 jan. 1950). Ao concluir, exaltou os argumentos que deveriam ser utilizados pelos paranaenses a fim de levar em frente a tão acalentada federalização, advogando os seguintes itens:

$$
\text { a) - A situação econômica do PARANÁ no seio da Federação; }
$$


b) - A existência de um grande patrimônio pertencente às escolas que formam a Universidade;

c) - Contarem as escolas da Universidade com mais de 37 anos de vida, sem interrupção;

d) - As magníficas condições do clima e de progresso que oferece a nossa Capital para a instituição de um grande centro universitário (GAZETA DO POVO, 19 jan. 1950).

Plínio Tourinho deteve-se em demonstrar argumentos contrários à federalização. Não obstante, reconheceu que estava consumada, pois havia entre os integrantes do mundo acadêmico e as lideranças políticas um ambiente favorável. Em síntese, é possível dizer que esse professor aceitou a federalização da UP. No entanto, mais do que ponderações e advertência, como destacou o jornal Gazeta do Povo, ele se posicionou contrariamente.

\title{
Conclusões
}

A posição de Tourinho em relação à federalização parece emblemática, pois ele integrou a alto-comando da UP, em particular da Faculdade de Engenharia. De sua exposição, identificamos sete argumentos que justificaram sua posição: 1) instituições privadas são menos onerosas, isto é, o dispêndio com a federalização seria maior do que a manutenção das subvenções; 2) universidades particulares são mais produtivas; 3) o patrimônio elevado acumulado pela Universidade do Paraná e grande número de estudantes; 4) ausência de autonomia financeira das instituições que já estavam federalizadas; 5) influência política que afetava a autonomia didática, financeira e administrativa; 6) burocracia da administração pública (centralização); 7) recursos insuficientes diante do grande número de instituições federalizadas. De outra parte, observamos apenas um elemento positivo com a federalização, a saber: melhoria no vencimento dos professores.

A legislação que tratou da federalização, em específico a lei 1.254 de 04 de dezembro de 1950, prescrevia no artigo 1은

\begin{abstract}
O sistema federal de ensino superior supletivo dos sistemas estaduais, será integrado por estabelecimentos mantidos pela União e por estabelecimentos mantidos pelos poderes públicos locais, ou por entidades de caráter privado, com economia própria, subvencionados pelo Govêrno Federal, sem prejuízo de outros auxílios que lhes sejam concedidos pelos poderes públicos (BRASIL, 1950).
\end{abstract}

No artigo $4^{a}$ previa-se que "Independente de qualquer indenização, são incorporados ao Patrimônio Nacional todos os bens móveis, imóveis e os direitos dos estabelecimentos federalizados pela presente Lei" (BRASIL, 1950). Já no artigo 5 estava prescrito: "É assegurado o aproveitamento no serviço público federal, a partir da publicação desta Lei, do pessoal dos estabelecimentos ora federalizados [...]" (BRASIL, 1950). A possibilidade de 
não federalização existia, pois o sistema federal de ensino superior se constituía por instituições federalizadas (mantidas diretamente pela União) e organizações subvencionadas pelo governo federal e administradas por outras esferas do Estado ou particulares, conforme determinava o artigo primeiro da Lei 254 de 4 de dezembro de 1950. A argumentação de Plínio Tourinho buscava enquadrar a UP nessa segunda possibilidade. Não obstante, a posição dele era solitária entre as lideranças da Universidade e entre as autoridades políticas paranaenses.

Muito embora, o Inquérito da Gazeta do Povo tenha publicado o posicionamento de Plínio Tourinho, ele deu maior visibilidade às posições da comunidade acadêmica e de outras lideranças curitibanas que eram favoráveis à federalização. $\mathrm{Na}$ condição de professor, Plínio Tourinho se manifestou contrário à federalização da UP. No entanto, na função de Diretor da Faculdade de Engenharia encaminhou e deliberou, em conjunto com os demais docentes, pela federalização. Essa situação reitera a disposição da comunidade acadêmica pelo processo de transformação da instituição paranaense em Universidade Federal. É importante reiterar que o reitor Flávio Suplicy, responsável pelo movimento de federalização, pertencia à Faculdade de Engenharia e mantinha uma boa relação com Plínio Tourinho (SOUZA, 2016).

A posição de Tourinho foi derrotada, pois a UP foi federalizada. Desde os anos 1940 havia um movimento em grande escala em prol da federalização de diversas universidades nos mais variados estados brasileiros. $O$ intenso processo de federalização representou que, em meados do século $X X$, grande parte das matrículas no ensino superior estava em instituições federais. De acordo com Ana Waleska Mendonça (2000, p. 141-142),

[...] o número de universidades existentes no país cresceu de 5, em 1945, para 37, em 1964. Na sua maioria eram universidades federais, criadas através do processo de federalização de faculdades estaduais ou particulares. A maioria das atuais universidades federais existentes hoje tem nesse processo a sua origem.

A lei que dispôs sobre o sistema federal de ensino (federalização de diversas universidades no ano de 1950) representou um salto no número de universidades existentes no país. Além disso, no caso da UP, conforme Névio de Campos (2013b, p. 93):

\footnotetext{
A federalização representou de modo imediato um aumento significativo do aporte de recursos financeiros. A principal evidência desse volume de recursos é a estruturação de obras. A primeira medida foi a ampliação e remodelação do prédio da Praça Santos Andrade. Em seguida, a construção do prédio do Hospital de Clínicas, inaugurado em 1960. Na sequência, os prédios da reitoria e Faculdades de Economia e Filosofia. Por fim, o Centro Politécnico.
}

Essas observações indicam que a federalização da UP garantiu o seu crescimento. No entanto, o temor apresentado por Plínio Tourinho de que os recursos se mostravam insuficientes ou a instituição não gozaria de autonomia financeira se fez presente, pois, 
alguns anos mais tarde, na reunião do Conselho Universitário de 26 de abril de 1968, o reitor Flávio Suplicy relatou que: "já faz seis meses e vinte e seis dias que não se recebia nenhuma contribuição para o custeio da Universidade" (SOUZA, 2016, p. 87). Além disso, a tão temida influência política se mostrou fortemente presente no regime militar, conforme atestam (MOTTA, 2008a, 2008b, 2010, 2011, 2014; MANSAN, 2013a, 2013b; SOUZA, 2016; PORTELA; SZESZ; LEITE, 2012).

A ideia da federalização prevaleceu na UP. Existia, a partir dos anos de 1930, conforme acentua Mônica Pimenta Velloso (2003, p. 148), a tendência a identificar no Estado "[...] a ideia de ordem, organização, unidade. Assim, ele é o cérebro capaz de coordenar e fazer funcionar harmonicamente todo o organismo social". Essa tendência é reiterada por Maria de Lourdes Fávero (2006, p. 23) nos seguintes termos:

\footnotetext{
Se a Primeira República é caracterizada pela descentralização política, a partir dos anos 20 e, sobretudo, após 1930, essa tendência se reverte, começando a se incrementar uma acentuada e crescente centralização nos mais diferentes setores da sociedade.
}

Esse temor de centralização aparecia na argumentação de Plínio Tourinho. Não obstante, entre os paranaenses o movimento em defesa da federalização seria unânime, não fosse a voz dissonante desse professor.

\section{Referências}

ALVES, Claudia. Dimensões da formação de intelectuais militares no século XIX. In: LEITE, Juçara Luzia; ALVES, Claudia (org.). Intelectuais e história da educação no Brasil: poder, cultura e políticas. Vitória: EDUFES, 2011. p. 85-110.

BARROS, Roque Spencer Maciel de. A ilustração brasileira e a ideia de universidade. São Paulo: EDUSP, 1986.

BONTEMPI JÚNIOR, Bruno. Nacionalismo e regionalismo em dois inquéritos sobre o Ensino Superior Brasileiro nos anos 1920. Educar em Revista, Curitiba, v. 33, p. 35-50, 2017.

BONTEMPI JÚNIOR, Bruno. O inquérito sobre a situação do ensino primário em São Paulo e suas necessidades (1914): análise das intervenções jornalísticas e políticas no discurso sobre a educação. Revista do Mestrado em Educação, São Cristóvão, v. 11, p. 43-50, 2005.

CAMPOS, Névio de. Flávio Suplicy de Lacerda: cruzada pela federalização e expansão da Universidade do Paraná. In: LEITE, Renato Lopes; OLIVEIRA, Ricardo Costa de (org.). Reflexões UFPR 100 anos (1912-2012). Curitiba: UFPR, 2013b. p. 71-101.

CAMPOS, Névio de. Intelectuais e sistema de ensino livre no Paraná na década de 1910. Revista de História Regional, Ponta Grossa, v. 18, n. 1, p. 62-85, $2013 a$.

CAMPOS, Névio de. Intelectuais paranaenses e as concepções de universidade (18921950). Curitiba: UFPR, 2008. 
CAPELATO, Maria Helena. Imprensa e história do Brasil. São Paulo: Contexto: Edusp, 1994.

CAPELATO, Maria Helena; PRADO, Maria Ligia. O bravo matutino - imprensa e ideologia: o jornal O Estado de São Paulo. São Paulo: Alfa-Omega, 1980.

CUNHA, Luiz Antônio. A universidade crítica: o ensino superior na República Populista. Rio de Janeiro: Francisco Alves, 1989.

CUNHA, Luiz Antônio. A universidade temporã: da Colônia a Era Vargas. Rio de Janeiro: Francisco Alves, 1986.

EVANGELISTA, Olinda. A formação universitária do professor: Instituto de Educação da Universidade de São Paulo (1934-1938). Florianópolis: Cidade Futura, 2002.

FÁVERO, Maria de Lourdes Albuquerque. A Universidade no Brasil: das origens à Reforma Universitária de 1968. Educar em Revista, Curitiba, n. 28, p. 17-36, 2006.

FÁVERO, Maria de Lourdes Albuquerque. A Universidade no Brasil: das origens à construção. Rio de Janeiro: UFRJ: INEP, 2000. v. 1.

LEITE, Renato Lopes; OLIVEIRA, Ricardo Costa de (org.). Reflexões UFPR 100 anos (1912-2012). Curitiba: UFPR, 2012.

LUCA, Tânia Regina. História dos, nos e por meio dos periódicos. In: PINSKY, Carla Bassanezi (org.). Fontes históricas. São Paulo: Contexto, 2005. p. 111-153.

MANSAN, Jaime Valim. A educação superior sob vigilância: o caso da DOPS/PR (19641988). Revista HISTEDBR, Campinas, v. 13, p. 14-26, $2013 a$.

MANSAN, Jaime Valim. Coerção e controle: a educação superior no Brasil durante a ditadura civil-militar (1964-1988). Clio, Recife, v. 30, p. 1-17, 2013 b.

MARTINS, Ana Luiza; LUCA, Tânia Regina de (org.). História da imprensa no Brasil. São Paulo: Contexto, 2008.

MENDONÇA, Ana Waleska Pollo Campos. A universidade no Brasil. Revista Brasileira de Educação, Rio de Janeiro, n. 14, p. 131-150, 2000.

MENDONÇA, Ana Waleska Pollo Campos. Anísio Teixeira e a universidade de educação. Rio de Janeiro: EDUERJ, 2002.

MOREL, Marco. Os primeiros passos da palavra impressa. In: MARTINS, Ana Luiza; LUCA, Tânia Regina de (org.). História da imprensa no Brasil. São Paulo: Contexto, 2008. p. 23-43.

MOTTA, Rodrigo Patto Sá. As universidades e o regime militar: cultura política brasileira e modernização autoritária. Rio de Janeiro: Zahar, 2014.

MOTTA, Rodrigo Patto Sá. Incômoda memória: os arquivos das ASI universitárias. Acervo, Rio de Janeiro, v. 16, p. 32-50, 2008b.

MOTTA, Rodrigo Patto Sá. Modernizando a repressão: a Usaid e a polícia brasileira. Revista Brasileira de História, São Paulo, v. 30, p. 237-266, 2010. 
MOTTA, Rodrigo Patto Sá. Os olhos do Regime Militar nos campi: as Assessorias de Segurança e Informações das Universidades. Topoi, Rio de Janeiro, v. 9, p. 30-67, 2008a.

MOTTA, Rodrigo Patto Sá. Repressão e resistência. Diálogos, Maringá, v. 15, p. 331-336, 2011.

OLIVEIRA, Ricardo Costa de. Teia do Nepotismo: sociologia política das relações de parentesco e poder político no Paraná e no Brasil. Curitiba: Insight, 2002.

PAULA, Maria de Fátima de. A modernização da universidade e a transformação da intelligentzia universitária. Florianópolis: Insular, 2002.

PORTELA, José Roberto Braga; SZESZ, Christiane Marques; LEITE, Renato Lopes. Contextos e traumas do maio de 1968 na UFPR. In: LEITE, Renato Lopes; OLIVEIRA, Ricardo Costa de (org.). Reflexões UFPR 100 anos (1912-2012). Curitiba: UFPR, 2012. p. 103-115.

PUPPI, Ildefonso Clemente. Fatos e reminiscências da faculdade: retrospecto da Escola de Engenharia da Universidade Federal do Paraná. Curitiba: Fundação da Universidade Federal do Paraná, 1986.

SOUZA, Eliezer Felix; CAMPOS, Névio de. Um inquérito sobre a federalização da Universidade do Paraná (1950). Revista Brasileira de História da Educação, Maringá, v. 17, n. 1, p. 140-166, jan./mar. 2017.

SOUZA, Eliezer. Felix. Flávio Suplicy de Lacerda: relações de poder no campo acadêmico/político paranaense e o processo de federalização e modernização da Universidade do Paraná (1930-1971). 2016. 303 f. Tese (Doutorado em Educação) Universidade Estadual de Ponta Grossa, Ponta Grossa, 2016.

VELLOSO, Mônica Pimenta. Os intelectuais e a política cultural do Estado Novo. In: FERREIRA, Jorge; DELGADO, Lucila de Almeida Neves (org.). O Brasil republicano: o tempo do nacional-estatismo do início da década de 1930 ao apogeu do Estado Novo. Rio de Janeiro: Civilização Brasiliense, 2003. p. 145-179.

VIEIRA, Carlos Eduardo. Imprensa, educação e esfera pública na década de 1920. In: CAMPOS, Névio de; SUASNABAR, Cláudio (org.). Educação no Brasil e na Argentina: escritos de história intelectual. Ponta Grossa: UEPG, 2013. p. 171-195.

VIEIRA, Carlos Eduardo. Jornal Diário como fonte e como tema para a pesquisa em História da Educação: um estudo da relação entre intelectuais, educação e modernidade. In: OLIVEIRA, Marcus Aurélio Taborda de (org.). Cinco estudos em História e Historiografia da Educação. Belo Horizonte: Autêntica, 2007. p. 11-40

WACHOWICZ, Ruy Christovam. Universidade do mate: história da UFPR. Curitiba: AFUFPR, 1983.

\section{Fontes}


BRASIL. Lei $n^{\circ} 1.254$, de 4 de dezembro de 1950. Dispõe sobre o sistema federal de ensino superior. Diário Oficial da União, Poder Executivo, Rio de Janeiro, 8 dez. 1950. Seção 1, p. 17537.

DIÁRIO DA TARDE. Curitiba, 28 de dezembro de 1949.

FACULDADE DE ENGENHARIA DO PARANÁ. Ata da Sessão da Congregação da Faculdade de Engenharia da Universidade do Paraná. Realizada 6 jul. 1946.

FACULDADE DE ENGENHARIA DO PARANÁ. Ata da Sessão da Congregação da Faculdade de Engenharia da Universidade do Paraná. Realizada 3 dez. 1946.

FACULDADE DE ENGENHARIA DO PARANÁ. Ata da Sessão da Congregação da Faculdade de Engenharia da Universidade do Paraná. Realizada 15 dez. 1946.

FACULDADE DE ENGENHARIA DO PARANÁ. Ata da Sessão da Congregação da Faculdade de Engenharia da Universidade do Paraná. Realizada 18 jan. 1948.

FACULDADE DE ENGENHARIA DO PARANÁ. Ata da Sessão da Congregação da Faculdade de Engenharia da Universidade do Paraná. Realizada 13 fev. 1948.

FACULDADE DE ENGENHARIA DO PARANÁ. Ata da Sessão da Congregação da Faculdade de Engenharia da Universidade do Paraná. Realizada 18 jun. 1948.

FACULDADE DE ENGENHARIA DO PARANÁ. Ata da Sessão da Congregação da Faculdade de Engenharia da Universidade do Paraná. Realizada 15 dez. 1948.

FACULDADE DE ENGENHARIA DO PARANÁ. Ata da Sessão da Congregação da Faculdade de Engenharia da Universidade do Paraná. Realizada 17 jan. 1950.

GAZETA DO POVO. Curitiba, 21 dez. 1949.

GAZETA DO POVO. Curitiba, 27 dez. 1949.

GAZETA DO POVO. Curitiba, 30 dez. 1949.

GAZETA DO POVO. Curitiba, 6 jan. 1950.

GAZETA DO POVO. Curitiba, 15 jan. 1950.

GAZETA DO POVO. Curitiba, 18 jan. 1950.

GAZETA DO POVO. Curitiba, 19 jan. 1950.

TOURINHO, Plínio Alves. Discurso (Pronunciado por ocasião da collação de grao da $1^{\text {a }}$ turma de Engenharia Civil da Universidade do Paraná). Revista Academica (Orgam do Centro Academico do Paraná), Curitiba, v. 3, n. 1-3, p. 11-28, abr. 1919.

UNIVERSIDADE DO PARANÁ. Relatório Geral. Curitiba, 1913.

Recebido em 28/05/2018

Aprovado em 21/11/2018 